\title{
On the structural and energetic properties of the hydrogen absorber $\operatorname{Li} 2 \mathrm{Mg}(\mathrm{NH}) 2$
}

C. Moysés Araújo

Uppsala Universitet, moyses.araujo@fysik.uu.se

Ralph H. Scheicher

Uppsala Universitet

Puru Jena

Virginia Commonwealth University, pjena@vcu.edu

Rajeev Ahuja

Uppsala Universitet

Follow this and additional works at: http://scholarscompass.vcu.edu/phys_pubs

Part of the Physics Commons

Araujo, C.M., Scheicher, R.H., Jena, P., et al. On the structural and energetic properties of the hydrogen absorber Li2Mg(NH)2. Applied Physics Letters, 91, 091924 (2007). Copyright (C) 2007 AIP Publishing LLC.

\section{Downloaded from}

http://scholarscompass.vcu.edu/phys_pubs/20

This Article is brought to you for free and open access by the Dept. of Physics at VCU Scholars Compass. It has been accepted for inclusion in Physics Publications by an authorized administrator of VCU Scholars Compass. For more information, please contact libcompass@vcu.edu. 


\title{
On the structural and energetic properties of the hydrogen absorber $\mathrm{Li}_{2} \mathrm{Mg}(\mathrm{NH})_{2}$
}

\author{
C. Moysés Araújo a) \\ Condensed Matter Theory Group, Department of Physics, Uppsala University, P.O. Box 530, S-751 21 \\ Uppsala, Sweden
}

Ralph H. Scheicher

Condensed Matter Theory Group, Department of Physics, Uppsala University, P.O. Box 530, S-751 21

Uppsala, Sweden and Department of Physics and Multi-Scale Technologies Institute, Michigan Technological University, Houghton, Michigan 49931

Puru Jena

Department of Physics, Virginia Commonwealth University, Richmond, Virginia 23284

Rajeev Ahuja

Condensed Matter Theory Group, Department of Physics, Uppsala University, P.O. Box 530, S-751 21

Uppsala, Sweden and Applied Materials Physics Group, Department of Materials and Engineering,

Royal Institute of Technology (KTH), S-100 44 Stockholm, Sweden

(Received 25 May 2007; accepted 2 August 2007; published online 31 August 2007)

The authors have performed density functional theory based calculations of several possible conformations for the crystal structure of $\mathrm{Li}_{2} \mathrm{Mg}(\mathrm{NH})_{2}$ and they confirm the $\alpha$ phase, resolved from both $\mathrm{x}$-ray and neutron diffraction data, as the ground-state configuration. It is also found that although the $\mathrm{N}-\mathrm{H}$ bond is stronger in $\mathrm{Li}_{2} \mathrm{Mg}(\mathrm{NH})_{2}$ than in $\mathrm{Li}_{2} \mathrm{NH}$, hydrogen release from $\mathrm{Li}_{2} \mathrm{Mg}(\mathrm{NH})_{2} / \mathrm{LiH}$ mixture displays more favorable thermodynamics than that from the $\mathrm{Li}_{2} \mathrm{NH} / \mathrm{LiH}$ mixture. The insights gained from this seemingly counterintuitive result should prove helpful in the search for promising hydrogen storage materials. (C) 2007 American Institute of Physics.

[DOI: $10.1063 / 1.2775803$ ]

A promising recent approach for efficient hydrogen storage ${ }^{1-7}$ considers the following reversible reaction without the need of any catalyst: ${ }^{8,9}$

$$
\mathrm{Mg}\left(\mathrm{NH}_{2}\right)_{2}+2 \mathrm{LiH} \leftrightarrow \mathrm{Li}_{2} \mathrm{Mg}(\mathrm{NH})_{2}+2 \mathrm{H}_{2} .
$$

Among the products that have been observed following the hydrogen release from $\mathrm{LiH} / \mathrm{Mg}\left(\mathrm{NH}_{2}\right)_{2}$ mixtures, $\mathrm{Li}_{2} \mathrm{Mg}(\mathrm{NH})_{2}$ is the one that has been least investigated in the literature so far. Only one very recent experiment has employed $\mathrm{x}$-ray and neutron diffraction measurements to investigate its structural properties in greater details. ${ }^{10} \mathrm{~A}$ deeper understanding of how $\mathrm{Li}$ mixes with $\mathrm{Mg}$, and how they both interact with $\mathrm{NH}$ units, could prove extremely valuable for future efforts in designing mixed compounds with suitable $\mathrm{H}$-storage properties. Theoretical studies can play an important role toward the achievement of this goal. ${ }^{11,12}$

In this letter, we present a theoretical investigation of the ground-state properties of this mixed $\mathrm{Li} / \mathrm{Mg}$ imide system and the thermodynamics of the hydrogen release. All calculations were carried out within the framework of the generalized gradient approximation ${ }^{13}$ to density functional theory ${ }^{14}$ by using the projector-augmented wave method, ${ }^{15}$ as implemented in the Vienna $a b$ initio simulation package (VASP). ${ }^{16}$ The $k$-points mesh was generated by the Monkhorst-Pack method, ${ }^{17}$ and all results were tested for convergence with respect to the mesh size. In all calculations, self-consistency was achieved with a tolerance in the total energy of $0.1 \mathrm{meV}$. For the geometry optimization, ${ }^{18,19}$ convergence required atomic forces of less than $0.001 \mathrm{eV} / \AA$. For high precision calculations, we used a cutoff energy of

${ }^{a)}$ Elecronic mail: moyses.araujo@fysik.uu.se
$520 \mathrm{eV}$ for the plane-wave basis. To further explore the potential energy surface of $\mathrm{Li}_{2} \mathrm{Mg}(\mathrm{NH})_{2}$, we have also performed $a b$ initio molecular dynamics ${ }^{16}$ simulated annealing calculations. Since we are dealing with a large system, the $\Gamma$-point alone was sufficient for sampling the Brillouin zone.

In this study, we considered six different structures as starting configurations from which geometry optimizations were initiated. Four of them are models constructed from the crystal structures of the compounds $\mathrm{Li}_{2} \mathrm{NH}$ and $\mathrm{LiNH}_{2}$. The other two are set up based on the low-temperature $\alpha$ phase of $\mathrm{Li}_{2} \mathrm{Mg}(\mathrm{NH})_{2} \cdot{ }^{10}$ In the first model, we add half as many $\mathrm{Mg}$ atoms to the $\mathrm{LiNH}_{2}$ unit cell as there are $\mathrm{Li}$ atoms present, and remove one $\mathrm{H}$ atom from every $\mathrm{NH}_{2}$ molecule, thus resulting in the desired stoichiometry of $\mathrm{Li}_{2} \mathrm{Mg}(\mathrm{NH})_{2}$. The detailed construction of this model can be described as follows. Two $\mathrm{Mg}$ atoms replace two $\mathrm{Li}$ atoms occupying $2 c$ sites $(0,0.5,0.25)$ in the $I-4$ space group $\left(\mathrm{LiNH}_{2}\right.$ crystal $\left.^{20}\right)$ and the displaced $\mathrm{Li}$ atoms are moved to $2 b$ sites $(0,0,0.5)$. Next, two more $\mathrm{Mg}$ atoms are placed at $2 d$ sites $(0,0.5$, $0.75)$. Finally, one hydrogen atom is removed from each $\mathrm{NH}_{2}$ unit. The resulting structure is illustrated in Fig. 1(a).

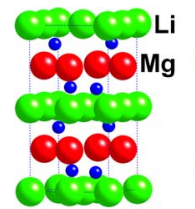

(a) model 1

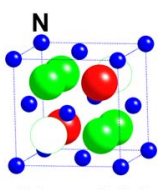

(b) model 2

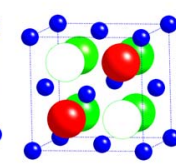

(c) model 3

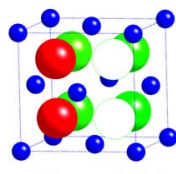

(d) model 4
FIG. 1. (Color online) Structure models 1-4 discussed in the text. Spheres in green, red, and blue color represent $\mathrm{Li}, \mathrm{Mg}$, and $\mathrm{N}$ atoms, respectively. For clarity the hydrogen atoms have been omitted. Vacancies are indicated by an opaque white sphere. 
Structural models $2-4$ have been motivated by the idea of inserting $\mathrm{Mg}$ into the $\mathrm{Li}_{2} \mathrm{NH}$ lattice, as illustrated by the following equation:

$$
\begin{aligned}
4 \mathrm{Li}_{2} \mathrm{NH} & =2 \mathrm{Li}_{2} \mathrm{NH}+2 \mathrm{Li}_{2} \mathrm{NH} \rightarrow 2 \mathrm{Li}_{2} \mathrm{NH}+2 \mathrm{MgNH} \\
& =2 \mathrm{Li}_{2} \mathrm{Mg}(\mathrm{NH})_{2} .
\end{aligned}
$$

Starting from the antifluorite structure of $\mathrm{Li}_{2} \mathrm{NH}$ with space group $F m-3 m$, which has been suggested from neutron and $\mathrm{x}$-ray diffraction measurements, ${ }^{21,22}$ we removed four of the eight $\mathrm{Li}$ ions in a unit cell, and put two $\mathrm{Mg}$ ions into two of the resulting vacancies [see Figs. 1(b)-1(d)]. There exist three possible ways to place the two $\mathrm{Mg}$ ions in distinctive configurations: Two $\mathrm{Mg}$ atoms on diagonally opposite corners of the cube (model 2), on opposite corners of one side of the cube (model 3), and on opposite ends of one edge of the cube (model 4). The hydrogen atoms were randomly placed at $48 h$ sites, one for each $\mathrm{N}$ atom. The atomic positions of all four structures models were subsequently fully optimized, without imposing any symmetry constraints.

We observed that the resulting structures were distorted from their originally tetragonal (model 1) or cubic symmetries (models 2-4) due to a decrease of the average distance between the cations ( $\mathrm{Li}$ and $\mathrm{Mg}$ ) and $\mathrm{N}$ atoms. This behavior is the consequence of balancing the attractive electrostatic and hard-core repulsive interactions, shown to be important for the determination of the ground-state crystal structure of $\mathrm{Li}_{2} \mathrm{NH}^{23}$ Another significant contribution when analyzing the properties of this imide system was found to be the repulsive electrostatic interaction between $\mathrm{H}$ and the cations ( $\mathrm{Li}$ and $\mathrm{Mg}$ ). The polar covalent bond within the $\mathrm{N}-\mathrm{H}$ units causes the $\mathrm{H}$ atoms to carry a partial positive charge. In order to minimize this contribution to the ground-state total energy, the $\mathrm{N}-\mathrm{H}$ units orient themselves with $\mathrm{H}$ pointing toward the vacant sites, as it has been observed previously from experimental results for this mixed compound, ${ }^{10}$ in a combined experimental and theoretical analysis of $\mathrm{Li}_{2} \mathrm{NH},{ }^{22}$ and in a theoretical study of $\mathrm{LiNH}_{2}$ and $\mathrm{Li}_{2} \mathrm{NH}$. ${ }^{24}$ This lowering of the repulsive electrostatic interaction manifests itself in the respective magnitudes of the cohesive energies per formula unit, which is defined as the total energy of the compound minus the sum of individual energy of atoms. We find the following hierarchy: model $4(-31.92$ $\mathrm{eV})>$ model $1(-32.57 \mathrm{eV})>$ model $2(-32.75 \mathrm{eV})>$ model $3(-32.86 \mathrm{eV})$. One can see that the most stable configuration is found to be the one in which the vacant sites in the cationic sublattice are distributed in the most uniform way [Fig. 1(d)], whereas the least stable configuration of the three lowenergy metastable structures is the one with the highest segregation between cations and vacancies [Fig. 1(b)].

To explore the potential energy surface of this compound more rigorously, we have also employed ab initio molecular dynamics simulations of a $2 \times 2 \times 2$ supercell constructed from the most stable structure (model 3 ). The following simulation set-up was employed: using a 1 fs time step throughout, the system was heated up for 2 ps at $1500 \mathrm{~K}$ and then subsequently cooled down to $100 \mathrm{~K}$ within $18 \mathrm{ps}$. In this simulation, the velocities are rescaled every other time step in order to keep control over the temperature, while in the intermediate steps a microcanonical simulation was employed. The radial distribution function $g(r)$, averaged over $1 \mathrm{ps}$, was recorded at $1500,900,700,500,300$, and $100 \mathrm{~K}$ (Fig. 2). At $1500 \mathrm{~K}$ and within the simulation time, we have

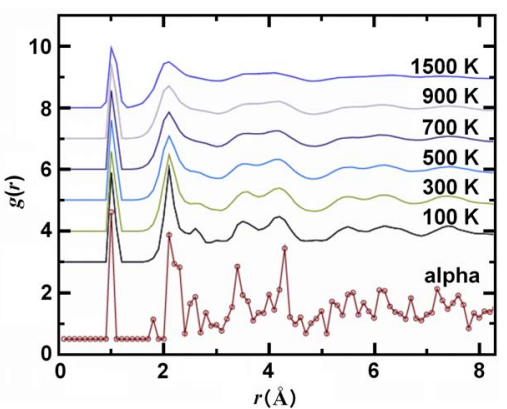

FIG. 2. (Color online) Radial distribution functions $g(r)$ averaged over $1 \mathrm{ps}$ each for different temperatures. The lines connecting the data points for the $\alpha$ phase are included as a guide to the eye.

observed the following atomic dynamics. The cations $\mathrm{Li}$ and $\mathrm{Mg}$ are actually found to diffuse in the supercell, with $\mathrm{Li}$ displaying a higher diffusion rate than $\mathrm{Mg}$. $\mathrm{H}$ atoms revolve around $\mathrm{N}$ atoms keeping the $\mathrm{N}-\mathrm{H}$ bond length virtually unchanged as it can also be observed from the sharp first peak of the $g(r)$ curve in Fig. 2, while the $\mathrm{N}$ atoms oscillate about their equilibrium position. As the system is cooled down, we observe the formation of increasingly deeper valleys and higher narrow peaks in the radial distribution function, indicating that the simulated system begins to recover its crystalline state. In order to investigate the structural properties of the ground state, we have performed a $0 \mathrm{~K}$ geometry optimization starting from the structure obtained at the end of the cooling process at $100 \mathrm{~K}$. The resulting configuration is displayed in Fig. 3(a). As can be observed, the structure displays a random distribution of $\mathrm{Li}$ and $\mathrm{Mg}$, much different from the ordered initial configuration of model 3. This result is also found to be in agreement with the structure proposed by Rijssenbeek et al. ${ }^{10}$ Such a degree of mixing between $\mathrm{Li}^{+}$ and $\mathrm{Mg}^{2+}$ is consistent with the fact that these two cations display similar ionic radii, namely, in units of Ångström, 0.59 (0.57), $0.76(0.72)$, and $0.92(0.89)$ for $\mathrm{Li}^{+}\left(\mathrm{Mg}^{2+}\right)$ with coordinations IV, VI, and VIII, respectively. This very close similarity in ionic radii $(<0.04 \AA)$ would not necessarily be expected for any arbitrary pair of cations, and it is thus quite unique for the combination $\mathrm{Li}-\mathrm{Mg}$. The effect of having the $\mathrm{N}-\mathrm{H}$ bonds oriented toward vacant sites (as observed in the initial model structures) is, however, found to be the same in this structure and, more importantly, the gain in energy was a mere $82 \mathrm{meV}$ per formula unit $\left(\mathrm{Li}_{2} \mathrm{Mg}(\mathrm{NH})_{2}\right)$, showing that the dominant contributions for the energetics have already been sampled in the configuration of model 3. It should also be pointed out that the simulated annealing calculations did not lead to any ordering of the cations vacancies.

The two models based on the low-temperature $\alpha$ phase of $\mathrm{Li}_{2} \mathrm{Mg}(\mathrm{NH})_{2}$ (Ref. 10) are constructed considering two distinct distributions of $\mathrm{Li}$ and $\mathrm{Mg}$ atoms for the optimization

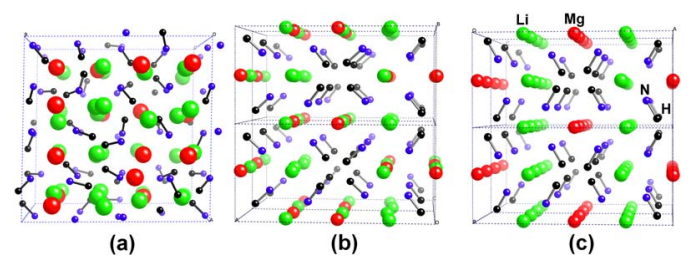

FIG. 3. (Color online) Structures of $\mathrm{Li}_{32} \mathrm{Mg}_{16}(\mathrm{NH})_{32}$ obtained from (a) $a b$ initio molecular dynamics simulated annealing calculations and geometry ontimization of (b) mixing and (c) segregation configurations. The green, red. blue, and black spheres represent $\mathrm{Li}, \mathrm{Mg}, \mathrm{N}$, and $\mathrm{H}$ atoms, respectively. 
to be initiated. In the first, $\mathrm{Li}$ and $\mathrm{Mg}$ fully occupy the $8 c$ and $4 b$ crystallographic sites ("segregation configuration"), respectively. In the second, these atoms are mixed in their occupancy of those sites ("mixing configuration"). The resulting structures are displayed in Figs. 3(b) and 3(c). The geometry optimization did not lead to any symmetry change, and furthermore, the calculated $\mathrm{N}-\mathrm{H}$ bond length of $1.04 \AA$ displays good agreement with the experimental value of $0.99 \AA$ A obtained from neutron diffraction data. ${ }^{10}$ The segregation configuration is very slightly lower in energy compared to the mixing configuration; however, the difference amounts to merely $7 \mathrm{meV}$. While there is, thus, virtually no preference for either configuration from an energetic point of view, it is more likely that $\mathrm{Li}$ and $\mathrm{Mg}$ will mix up in the cation sublattice, simply due to the higher likelihood for such disordered configurations.

The main result of our investigation is that we found the $\alpha$ phase to be the most stable one among all the conformations studied in this work. The corresponding total energy is around $210 \mathrm{meV}$ lower than that of the structure displayed in Fig. 3(a). We attribute this energy gain to the vacancies ordering, which highly optimizes the electrostatic interactions in this system. For comparison, we have also evaluated the $g(r)$ function for the optimized $\alpha$ phase, which is displayed in Fig. 2. One can see a qualitative agreement with the $g(r)$ curve at $100 \mathrm{~K}$. The only major difference is the presence of a peak at around $1.8 \AA$ in the $\alpha$ phase, due to $\mathrm{H}-\mathrm{H}$ pairing, a signature of the $\mathrm{N}-\mathrm{H}$ bond orientation ordering.

To compare the strength of the chemical bonds holding hydrogen atoms in the mixed $\mathrm{Li} / \mathrm{Mg}$ and in the pure $\mathrm{Li}$ imide systems, we have evaluated the hydrogen removal energies in these two systems, which are defined as $\Delta E_{H}\left(\mathrm{Li}_{2} \mathrm{NH}\right)=E_{T}\left(\mathrm{Li}_{8} \mathrm{~N}_{4} \mathrm{H}_{3}\right)+\frac{1}{2} E_{T}\left(\mathrm{H}_{2}\right)$ $-E_{T}\left(\mathrm{Li}_{8} \mathrm{~N}_{4} \mathrm{H}_{4}\right)$ and $\Delta E_{H}\left(\mathrm{Li}_{2} \mathrm{Mg}(\mathrm{NH})_{2}\right)=E_{T}\left(\mathrm{Li}_{8} \mathrm{Mg}_{4} \mathrm{~N}_{8} \mathrm{H}_{7}\right)$ $+\frac{1}{2} E_{T}\left(\mathrm{H}_{2}\right)-E_{T}\left(\mathrm{Li}_{8} \mathrm{Mg}_{4} \mathrm{~N}_{8} \mathrm{H}_{8}\right)$, where $E_{T}\left(\mathrm{Li}_{8} \mathrm{~N}_{4} \mathrm{H}_{4}\right)$, $E_{T}\left(\mathrm{Li}_{8} \mathrm{~N}_{4} \mathrm{H}_{3}\right), \quad E_{T}\left(\mathrm{Li}_{8} \mathrm{Mg}_{4} \mathrm{~N}_{8} \mathrm{H}_{8}\right), \quad E_{T}\left(\mathrm{Li}_{8} \mathrm{Mg}_{4} \mathrm{~N}_{8} \mathrm{H}_{7}\right)$, and $E_{T}\left(\mathrm{H}_{2}\right)$ are the ground-state total energies of $\mathrm{Li}_{8} \mathrm{~N}_{4} \mathrm{H}_{4}$, $\mathrm{Li}_{8} \mathrm{~N}_{4} \mathrm{H}_{3}, \mathrm{Li}_{8} \mathrm{Mg}_{4} \mathrm{~N}_{8} \mathrm{H}_{8}$, and $\mathrm{Li}_{8} \mathrm{Mg}_{4} \mathrm{~N}_{8} \mathrm{H}_{7}$ cells and $\mathrm{H}_{2}$ molecule in the gas phase, respectively. For $\mathrm{Li}_{2} \mathrm{Mg}(\mathrm{NH})_{2}$, we have used the optimized structure shown in Fig. 3(b). To calculate the energy of the $\mathrm{H}_{2}$ molecule, we have employed the supercell approach. For Li imide the orthorhombic structure (space group Pnma) proposed by Magyari-Köpe et al. ${ }^{23}$ was used. We have found hydrogen removal energies of $2.45 \mathrm{eV}$ for $\mathrm{Li}_{2} \mathrm{Mg}(\mathrm{NH})_{2}$ and $2.42 \mathrm{eV}$ for $\mathrm{Li}_{2} \mathrm{NH}$, showing that the $\mathrm{N}-\mathrm{H}$ bond is somewhat stronger in the former. This can be understood from the repulsive effect that nearby $\mathrm{Li}$ cations in $\mathrm{Li}_{2} \mathrm{NH}$ have on the partial positive charge of hydrogen in $\mathrm{NH}$, while the hydrogen atoms in $\mathrm{Li}_{2} \mathrm{Mg}(\mathrm{NH})_{2}$ can avoid such repulsive interactions by orienting themselves toward the cation vacancy sites.

To investigate the thermodynamics of hydrogen release reaction from the mixture of $\mathrm{Li}_{2} \mathrm{Mg}(\mathrm{NH})_{2}$ and $\mathrm{LiH}$, which allows us to draw comparisons with the thermodynamics of hydrogen release from the mixture of $\mathrm{Li}_{2} \mathrm{NH}$ and $\mathrm{LiH}$, we have evaluated the zero-temperature enthalpy of the following reaction (cf., Ref. 10):

$$
3 \mathrm{Li}_{2} \mathrm{Mg}(\mathrm{NH})_{2}+2 \mathrm{LiH} \rightarrow 4 \mathrm{Li}_{2} \mathrm{NH}+\mathrm{Mg}_{3} \mathrm{~N}_{2}+2 \mathrm{H}_{2},
$$

where $\mathrm{Mg}_{3} \mathrm{~N}_{2}$ is a semiconductor that crystallizes in a cubic structure with space group Ia-3. Such enthalpy is given by the sum of the electronic total energy, zero point vibration energy, and the $p V$ term. Actually, the latter has been neglected in this work. We have found the reaction above to be endothermic with an enthalpy of $84.1 \mathrm{~kJ}\left(\mathrm{~mol} \mathrm{H}_{2}\right)^{-1}$. Since the transition temperature for this kind of reaction is highly dominated by the hydrogen gas entropy, the reaction in Eq. (3) may take place at lower temperature than $\mathrm{Li}_{2} \mathrm{NH}+\mathrm{LiH}$ $\rightarrow \mathrm{Li}_{3} \mathrm{~N}+\mathrm{H}_{2}$ (Ref. 25) for which we have found an enthalpy of $118 \mathrm{~kJ}\left(\mathrm{~mol} \mathrm{H}_{2}\right)^{-1}$.

In summary, by means of first-principles calculations, we confirm the $\alpha$ phase, ${ }^{10}$ as the ground-state configuration of $\mathrm{Li}_{2} \mathrm{Mg}(\mathrm{NH})_{2}$. The partially positively charged $\mathrm{H}$ atoms of the covalently bound $\mathrm{NH}$ units orient themselves toward the cation vacancies, thus minimizing the repulsive electrostatic interaction between hydrogen and cations. The ordering of such vacancies is found to be an important contribution to minimize the total energy. Very similar strengths for the chemical bonds holding hydrogen atoms in both $\mathrm{Li}_{2} \mathrm{Mg}(\mathrm{NH})_{2}$ and $\mathrm{Li}_{2} \mathrm{NH}$ were found. Despite this result, the further hydrogen release process from the mixture of $\mathrm{Li}_{2} \mathrm{Mg}(\mathrm{NH})_{2}$ and $\mathrm{LiH}$ is improved compared to that from the mixture of $\mathrm{Li}_{2} \mathrm{NH}$ and $\mathrm{LiH}$. This is a consequence of the stable byproducts, which are formed following the $\mathrm{H}$ release.

The authors are grateful to the Swedish National Infrastructure (SNIC) for computing time. Financial support from STINT, VR, FUTURA and EXC!TiNG (EU Research and Training Network) is also acknowledged. One of the authors (P.J.) acknowledges support from the Department of Energy.

${ }^{1}$ M. S. Dresselhaus and I. L. Thomas, Nature (London) 414, 332 (2001).

${ }^{2}$ J. S. Rigden, Hydrogen: The Essential Element (Harvard University Press, Cambridge, MA, 2003), p. 1.

${ }^{3}$ W. Grochala and P. P. Edwards, Chem. Rev. (Washington, D.C.) 104, 1283 (2004).

${ }^{4}$ J. Alper, Science 299, 1686 (2003).

${ }^{5}$ R. D. Cortright, R. R. Davda, and J. A. Dumesic, Nature (London) 418, 964 (2002).

${ }^{6}$ N. L. Rosi, J. Eckert, M. Eddaoudi, D. T. Vodak, J. Kim, M. O. Keefe, and M. Yagh, Science 300, 1127 (2003).

${ }^{7}$ L. Schlappbach and A. Züttel, Nature (London) 414, 353 (2001).

${ }^{8}$ W. Luo, J. Alloys Compd. 381, 284 (2004).

${ }^{9}$ Z. Xiong, G. Wu, J. Hu, and P. Chen, Adv. Mater. (Weinheim, Ger.) 16, 1522 (2004).

${ }^{10}$ J. Rijssenbeek, Y. Gao, J. Hanson, Q. Huang, C. Jones, and B. Toby, J. Alloys Compd. (in press).

${ }^{11}$ O. M. Løvvik and O. Swang, Europhys. Lett. 67, 607 (2004).

${ }^{12}$ M. E. Arroyo y de Dompablo and G. Ceder, J. Alloys Compd. 364, 6 (2004).

${ }^{13}$ J. P. Perdew and Y. Wang, Phys. Rev. B 45, 13244 (1992).

${ }^{14}$ W. Kohn and L. J. Sham, Phys. Rev. 140, A1133 (1965).

${ }^{15}$ P. E. Blöchl, Phys. Rev. B 50, 17953 (1994).

${ }^{16}$ G. Kresse and J. Furthmüller, Phys. Rev. B 54, 11169 (1996).

${ }^{17}$ H. J. Monkhorst and J. D. Pack, Phys. Rev. B 13, 5188 (1976).

${ }^{18}$ W. H. Press, B. P. Flannery, S. A. Tenkolsky, and W. T. Vetterling, Numerical Recipes (Cambridge University Press, New York, 1986), Vol. 1.

${ }^{19}$ P. Pulay, Chem. Phys. Lett. 73, 393 (1980).

${ }^{20}$ J. B. Yang, X. D. Zhou, Q. Cai, W. J. James, and W. B. Yelon, Appl. Phys. Lett. 88, 041914 (2006).

${ }^{21}$ T. Noritake, H. Nozaki, M. Aoki, S. Towata, G. Kitahara, Y. Nakamori, and S. Orimo, J. Alloys Compd. 393, 264 (2005).

${ }^{22}$ M. P. Balogh, C. Y. Jones, J. F. Herbst, L. G. Hector, Jr., and M. Kundrat, J. Alloys Compd. 420, 326 (2006).

${ }^{23}$ B. Magyari-Köpe, V. Ozolins, and C. Wolverton, Phys. Rev. B 73, 220101(R) (2006).

${ }^{24}$ J. F. Herbst and L. G. Hector, Jr., Phys. Rev. B 72, 125120 (2005).

${ }^{25}$ P. Chen, Z. Xiong, J. Luo, J. Lin, and K. L. Tan, Nature (London) 429, $302(2002)$ 